\title{
Tobermorite Microstructure Resulted from Reaction of Low Content of Silica of Rice Husk Ash and Quicklime Mixture
}

\author{
Bakri $^{\#}$ \\ ${ }^{\#}$ Department of Foresty, Hasanuddin University, JL. Perintis Kemerdekaan KM. 10, Makassar,90245, Indonesia \\ E-mail:bakrifhut@unhas.ac.id
}

\begin{abstract}
Tobermorite is a hydration product resulted from hydration process of cementitious material, and it has the most important role among the other hydration products in concrete and mortar because of its stiffness and strength. Most of the cementitious materials used for making concrete and mortar in the construction industry originate from the nonrenewable material. Due to the environmental issues, renewable materials such as rice husk ash are proposed to be used as supplementary or substitution for the nonrenewable cementitious material. This study aimed to investigate the presence of tobermorite resulted after hydration process of a mixture of low content silica of rice husk ash and quicklime. Rice husk ash used in this study containing silica (SiO2) of $69.42 \%$ and quicklime containing calcium oxide $(\mathrm{CaO})$ of $95.75 \%$. Samples in powder form to determine the presence of tobermorite were analyzed by using X-ray diffractometer Bruker D8 Focus and micrographs of microstructure were analyzed by using SEM JEOL 7000F. Powder samples were originated from samples in cube form of a mixture of rice husk ash and quicklime. Samples of $1 \mathrm{~cm}^{3}$ were made by using 5 mixture ratios of rice husk ash and quicklime namely $0.25: 0.75,0.35: 0.65,0.50: 0.50,0.65: 0.35$, and $0.75: 0.25$. 28 days curing time of samples needed before converted to powder form. The results of XRD analysis show that no tobermorite formation presented in a mixture ratio of $0.25: 0.75 \mathrm{and} 0.35: 0.6$, while the presence of tobermorite formation showed in a mixture ratio of $0.50: 0.50,0.65: 0.35$, and $0.75: 0.25$. But SEM analysis found jennite microstructure, a mineral looks like a tobermorite, in a mixture of rice husk ash and quicklime at a ratio of $0.25: 0.75$.
\end{abstract}

Keywords - tobermorite; hydration process; rice husk ash; quicklime; x-ray diffractometer; microstructure; mixture ratio

\section{INTRODUCTION}

Increasing the use of cement in the various sectors spurring the production of cement while this industry still contributes quite large quantity of gas emissions of $\mathrm{CO}_{2}$ into the air. Carbonate oxidation in clinker production stage and fuel combustion are the main sources to generate $\mathrm{CO}_{2}$ emissions in cement manufacturing. Clinker production process and fuel combustion contributing to about $8 \%$ of the total global $\mathrm{CO}_{2}$ emissions in 2014 in [1]. 0.94 ton of $\mathrm{CO}_{2}$ will be released into the air to produce 1 ton of ordinary Portland cement through those two processes [2].

Efforts to reduce $\mathrm{CO}_{2}$ emissions in cement manufacturing process can now be achieved by using pozzolanic materials as supplementary to the clinker. The Pozzolanic material is a material containing silica and alumina when mixed with calcium hydroxide in the presence of water will produce compounds having similar characteristics of cement. The use of pozzolanic materials as a partial cement replacement in blended cement and concrete can reduce $\mathrm{CO}_{2}$ emission, increase concrete performance and reduce energy consumption in cement and concrete production [3], [4]. The reduction of the proportion of clinker through the addition of supplementary materials is also more profitable because of the lower cost of cement production. In recent years, many cement industries have been using natural pozzolan because of the lower cost.

Cheap and green materials obtained from industrial waste and agricultural by-products can be used to gain success in reducing $\mathrm{CO}_{2}$ and cost production in cement manufacturing [5]. Therefore, the development of the use of natural pozzolan from industrial waste and agricultural by-products to reduce material cost of construction is now more attractive in the world [6]. Some types of earth minerals and plant substances can be found in many places in the world as cheap sources of pozzolanic materials to produce cheap construction materials, but their utilization is still partially accomplished [7].

Rice husk as an important rice husk ash source to produce pozzolanic material is an example of a natural material for the cement manufacture. Rice husk is one of the main agricultural by-products in Indonesia, and other rice producer countries yielded after rice milling process. Accounted for more than 80 million tons of rice husks produced annually by those rice producer countries to produce about 3.2 million tons of silica [8]. Some studies 
have found that rice husk ash can be obtained from rice husk by burning the rice husk at a high temperature.

High amorphous silica can be extracted from rice husk by burning rice husk at a temperature below $700{ }^{\circ} \mathrm{C}$. As a pozzolanic material, rice husk ash is characterized by its important properties in the production and use of cement and concrete [9]. Use of rice husk ash as a partial replacement of cement production in concrete application improving concrete performance because of the increase of calcium silicate hydrate formation in concrete [10]. Pozzolan has a role in cement reaction with lime and another alkali [7].

The main chemical substance of rice husk ash is siliceous material that can be used to make a cheap pozzolanic cement by mixing with a calcareous material such as quicklime. Quicklime mixed with pozzolan when added with water will produce important compounds of calcium silicate hydrate (tobermorite) and other compounds such as calcium hydroxide (portlandite) and calcium carbonate (calcite) during the hydration process. Amorphous silica of rice husk ash is a highly reactive pozzolanic material that is suitable for use in a mixture of lime and pozzolan as a substitute for Portland cement [11]. Study of the pozzolanic activity with lime to replace cement usage is becoming increasingly important because of the need for more sustainable cementitious products.

A mixture of pozzolanic materials with lime will results in similar properties of other cement-based materials so when it is mixed with water, a number of chemical reactions will take place. These chemical reactions grow up simultaneously or successively an exothermic temperature during the hydration process. The main hydration products of the cement-based materials produced during the hydration process are calcite, portlandite, ettringite, gel and capillary pores, and tobermorite. But the presence of tobermorite as hydration product at all times raises more significance because it is responsible for the concrete strength. The main aim of this study was to investigate the presence of tobermorite resulted after hydration process of a mixture of low content silica of rice husk ash and quicklime. The presence of calcite and portlandite as other two primary hydration products in the mixture were also investigated. The presence of the all hydration products in the mixture was investigated by using X-ray diffractogram (XRD) and Scanning Electron Microscopy (SEM) analysis.

\section{MATERIAL AND METHOD}

\section{A. Material and Equipment}

Materials used in this study were quicklime, rice husk ash, and distilled water. Rice husk ash was produced by adopting a method of [12], while quicklime obtained from local producers in Makassar, province of South Sulawesi, Indonesia. Research equipment consists of furnace types Barnsted Thermolyne 1400, measuring cups, digital scales, thermometer, hygrometer caliper, molder cube of $50 \mathrm{x} 50 \mathrm{x}$ $50 \mathrm{~mm}$, basins, buckets, plastic bag, cormorant aluminum, drum, sieve, mixer, furnace, diffraction -X Bruker D8 Focus and SEM JEOL 7000F.

\section{B. Manufacturing and Chemical Analysis of Materials}

Rice husk ash manufacturing was carried out in the laboratory of utilization and forest product processing Hasanuddin University, Indonesia. Rice husk washed by using distilled water and dried until reaching air dried moisture content. Rice husks burned to convert in the charcoal form in a drum at a temperature of $\pm 300^{\circ} \mathrm{C}$ for 60 minutes. Charcoal of rice husk was then cooled in the aluminum drum for 24 hours. Cooled rice husk then burned to convert to ashes form in the furnace-type Barnsted Thermolyne 1400 at a temperature of $600{ }^{\circ} \mathrm{C}$ for 2 hours. Rice husk ash cooled and grounded by using a blender for 30 minutes. Rice husk ash was then filtered by using a 325 mesh sieve and stored in a plastic bag before used. Analysis of the chemical composition of rice husk ash and quicklime was conducted by adopting the chemical analysis of Indonesian Portland cement [13].

\section{XRD and SEM analysis of Samples}

Five samples of the mixture of rice husk ash and quicklime were made in cube form $(1 \times 1 \times 1 \mathrm{~cm})$ for XRD and SEM analysis of. Each sample was made by using a different mixture ratio of rice husk ash : quicklime based on the mixture weight that were 0.25: 0.75 (sample A), 0.35: 0.65 (sample B), 0.5: 0.5 (sample C), 0.65: 12:35 (sample D) and 0.75: 0.25 (sample E). Rice husk ash and quicklime of any mixture ratio was blended in a mixer for 3 minutes then added with distilled water as much as 0.6 of the mixture weight of rice husk ash and quicklime and stirred for 2 minutes. The mixture was then inserted into an iron molder of $1 \times 1 \times 1 \mathrm{~cm}$. The mixtures were allowed to harden for 24 hours in the iron molder and then released and stored in humid conditions and a temperature of $25^{\circ} \mathrm{C}$ for 28 days. $\mathrm{XRD}$ and SEM analysis of mixtures were carried out in the laboratory of Material Sciences, University of Washington, USA. X-ray diffractogram of sample powder was conducted by using a Bruker D8 Focus via $\mathrm{Cu} \mathrm{K \alpha}$ radiation at $40 \mathrm{Mv}$ and $40 \mathrm{~mA}$ with peaks analyzed at $2 \theta=10^{\circ}$ to $90^{\circ}$. The micrographs of the sample obtained from observation through SEM by using JEOL 7000F type.

\section{RESUlts AND DisCUSSION}

\section{A. Materials Properties}

Table 1 shows that most of the properties of rice husk ash and quicklime used in this study are composed of the same oxides but with different contents. The main oxide of rice husk ash is $69.42 \%$ of $\mathrm{SiO}_{2}$, while quicklime is $93.75 \%$ of $\mathrm{CaO} . \mathrm{SiO}_{2}$ is the most important compound of material to be used as raw material for cement matrix. $\mathrm{SiO}_{2}$ provides a pozzolanic property to the cement to produce hydration products so that strength is developed in the cement matrix system. A mixture of $\mathrm{SiO}_{2}$ of rice husk ash and $\mathrm{CaO}$ of quicklime will generate cementitious material $\left(\mathrm{CaOSiO}_{2}\right)$ and if added with water will produce tobermorite. LOI contents of rice husk ash are quite large namely $21.43 \%$. The percentage of rice husk ash that did not pass a sieve of 12 $\mu \mathrm{m}$ is $25 \%$ indicate that rice husk ash contains a lot of large particle size. LOI content and the large particle size of rice husk ash would be a constraint factor influencing the tobermorite formation during the hydration process. 
TABLE I

RICE HUSK ASH AND QUiCKLIME PROPERTIES

\begin{tabular}{|l|l|l|}
\hline Properties & Rice Husk Ash & Quicklime \\
\hline Bulk Density $\left(\mathrm{kgm}^{-3}\right)$ & 760 & 710 \\
\hline Not pass on $12 \mu \mathrm{m}$ sieve $(\%)$ & 25 & 5 \\
\hline $\mathrm{SiO}_{2}(\%)$ & 69.42 & NA \\
\hline $\mathrm{Al}_{2} \mathrm{O}_{3}(\%)$ & 0.37 & 1.05 \\
\hline $\mathrm{Fe}_{2} \mathrm{O}_{3}(\%)$ & 0.32 & 0.70 \\
\hline $\mathrm{CaO}(\%)$ & 0.65 & 93.75 \\
\hline $\mathrm{MgO}(\%)$ & NA & 1.85 \\
\hline $\mathrm{Na} 2 \mathrm{O}(\%)$ & NA & 0.23 \\
\hline $\mathrm{K}_{2} \mathrm{O}(\%)$ & NA & 0.88 \\
\hline $\mathrm{LOI}(\%)$ & 21.43 & 1.54 \\
\hline
\end{tabular}

Remarks: NA = Not Applicable, LOI $=$ Lost of Ignition

The large percentage of LOI and particles of rice husk ash that did not pass on a $12 \mu \mathrm{m}$ sieve may be caused by the short time to burn rice husk before converting to ash. The length of time to convert rice husk to rice husk charcoal before conditioning the rice husk charcoal to be rice husk ash was only 60 minutes. It was necessary to burn rice husk over 60 minutes but not exceed to 90 minutes to get smaller particle size, to reduce LOI, and to obtain a large percentage of silica content of the rice husk ash. The method to ground the rice husk ash only by using blender also predicted as another factor causing the large size of a particle of rice husk ash.

The minor oxides found in rice husk ash including $\mathrm{Al}_{2} \mathrm{O}_{3}$ $(0.37 \%), \mathrm{Fe}_{2} \mathrm{O}_{3}(0.32 \%)$, and $\mathrm{CaO}(0.65 \%)$. While the minor oxides found in quicklime including $\mathrm{Al}_{2} \mathrm{O}_{3}(1.05 \%), \mathrm{Fe}_{2} \mathrm{O}_{3}$ $(0.70 \%), \mathrm{MgO}(1.85 \%), \mathrm{Na}_{2} \mathrm{O}(0.23 \%)$, and $\mathrm{K}_{2} \mathrm{O}(0.88 \%)$. It has been widely accepted that the chemical composition of rice husk is found to vary from one place to another due to the differences in the type of paddy, crop year, climate and geographical conditions, so the chemical composition of rice husk ash is also various.

According to the XRD graph in Fig. 1, the mixture of rice husk ash and quicklime was mainly in amorphous form as shown by the broad peak on the $2 \theta$ angle of $22^{\circ}$.

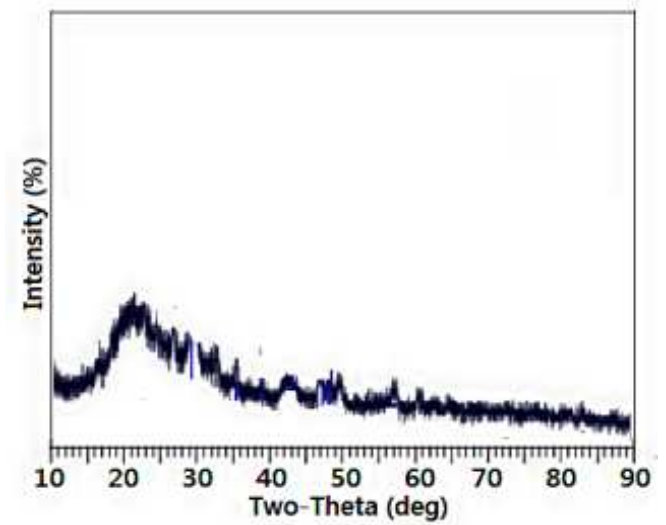

Fig. 1 XRD spectrum of Mixture of Rice Husk Ash and Quicklime

\section{B. XRD Analysis}

$\mathrm{XRD}$ diffraction pattern of sample $\mathrm{A}$ and $\mathrm{B}$ is shown in Fig. 2 and 3 and sample C, D, and E shown in Fig. 4, 5 and
6 respectively. XRD diffraction pattern of sample A containing a mixture ratio of rice husk ash and quicklime 0.25: 0.75 in Fig. 2 and XRD diffraction pattern of sample B containing a mixture ratio of rice husk ash and quicklime 0.35: 0.65 in Fig. 3 have a similar diffraction pattern but with different intensities. Peaks of XRD diffraction pattern of sample A and B detected the presence of calcite $\left(\mathrm{Ca}\left(\mathrm{CO}_{3}\right)\right)$ which can be seen at $2 \theta$ around $23.10^{\circ}, 29.10^{\circ}, 36.15^{\circ}$, $39.10^{\circ}, 43.21^{\circ}, 47.42^{\circ}, 48.75^{\circ}, 56.47^{\circ}, 57.39^{\circ}, 61.85^{\circ}$, and $64.80^{\circ}$ and portlandite $\left(\mathrm{Ca}(\mathrm{OH})_{2}\right)$ which can be seen at $2 \theta$ around $18.10^{\circ}, 28.45^{\circ}, 34^{\circ}, 47.29^{\circ}, 50.85^{\circ}, 53.30^{\circ}, 62.87^{\circ}$, $72^{\circ}$ and $84.90^{\circ}$. The intensity difference between the XRD diffraction pattern of the sample $\mathrm{A}$ and $\mathrm{B}$ shows that the intensity of calcite $\left(\mathrm{Ca}\left(\mathrm{CO}_{3}\right)\right)$ and portlandite $\left(\mathrm{Ca}(\mathrm{OH})_{2}\right)$ in sample A decreases with the increasing ratio of rice husk ash and the decreasing ratio of quicklime in the mixture ratio of sample B.

Fig. 2 and 3 show also that the XRD diffraction pattern of the sample A and B differ from XRD diffraction pattern of sample C, D, and E, while sample C, D, and E have similar XRD diffraction pattern. Fig. 2 and 3 show that the presence of tobermorite $\left(3 \mathrm{CaO} .2 \mathrm{SiO}_{2} \cdot 3 \mathrm{H}_{2} \mathrm{O}\right)$ in sample $\mathrm{A}$ and $\mathrm{B}$ cannot be detected because there was no tobermorite formed by reaction between the chemical compound of rice husk ash and quicklime in the two mixture ratios. Cao of quicklime reacted with $\mathrm{CO}_{2}$ and $\mathrm{H}_{2} \mathrm{O}$ to form $\mathrm{Ca}\left(\mathrm{CO}_{3}\right)$ (calcite) and $\mathrm{Ca}(\mathrm{OH})_{2}$ (portlandite), while this portlandite did not react with $\mathrm{SiO}_{2}$ of rice husk ash and $\mathrm{H}_{2} \mathrm{O}$ to form tobermorite. Fig. 2 and 3 show that most of the reactions occurred between $\mathrm{CaO}$ and $\mathrm{CO}_{2}$ to form calcite.

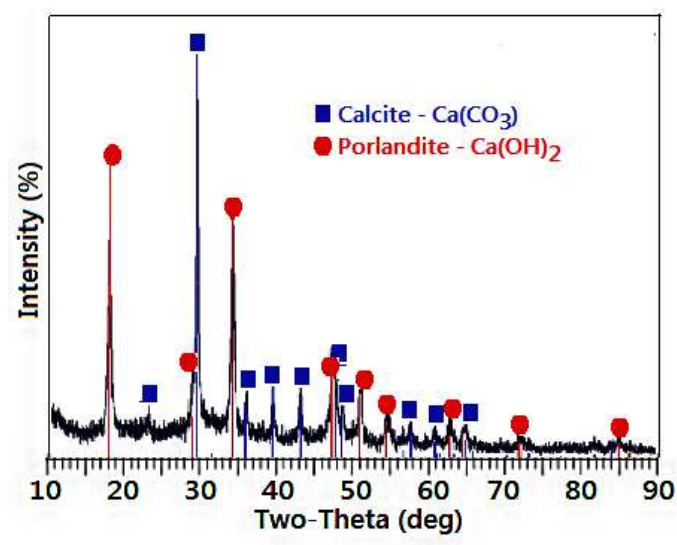

Fig. 2 XRD diffraction pattern of sample A

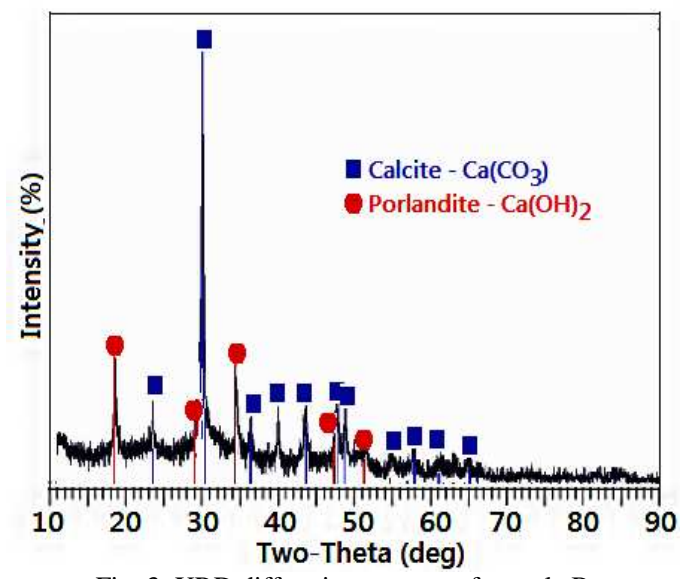

Fig. 3 XRD diffraction pattern of sample B 
Fig. 4, 5 and 6 show that sample C, D, and E did relatively not contain more portlandite, whereas they still contained a relatively equal intensity of calcite. Fig. 4, 5 and 6 also show the presence of tobermorite in sample C, D and E containing lower intensities than calcite. Although it was very difficult to detect the peaks of tobermorite in XRD diffraction pattern of sample $\mathrm{C}, \mathrm{D}$, and $\mathrm{E}$, at least there were three peaks of tobermorite in XRD diffraction pattern which can be detected at $2 \theta$ around $29.93^{\circ}, 32.49^{\circ}$, and $49.87^{\circ}$. By investigating at tobermorite peaks, they apparently situated in the same point of portlandite position in XRD diffraction pattern indicating that portlandite reacted with silica to form tobermorite. But the lack of tobermorite concentration in sample C, D, and E shown by detecting tobermorite peaks in $\mathrm{XRD}$ diffraction pattern may cause by less reactive of some silica of rice husk ash used in this study due to the small surface area of the silica.

Fig. 2, 3, 4, 5 and 6 show that there is an amorphous silicate hump located appearing like a band form. The amorphous silicate hump is definitely not tobermorite because tobermorite has a specific crystallographic structure that would show up in the XRD pattern. The amorphous silicate hump in those figures is not necessarily $\mathrm{SiO}_{2}$, but it is dominated by amorphous $\mathrm{SiO}_{2}$. The intensity of amorphous $\mathrm{SiO}_{2}$ is more increased with the increase of silica of rice husk ash ratio in the mixture. This proves that does not all $\mathrm{SiO}_{2}$ react with portlandite to form tobermorite as shown especially in Fig. 4, 5 and 6. Therefore, although increasing of silica ratio in the mixture, the tobermorite concentration formed remains relatively similar.

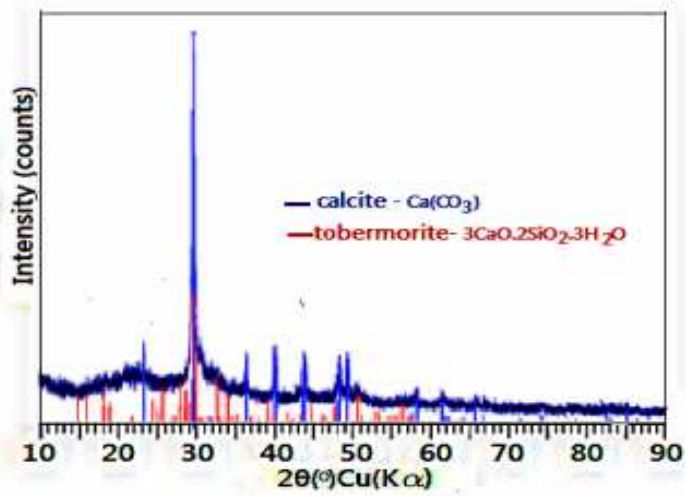

Fig. 4 XRD diffraction pattern of sample $\mathrm{C}$

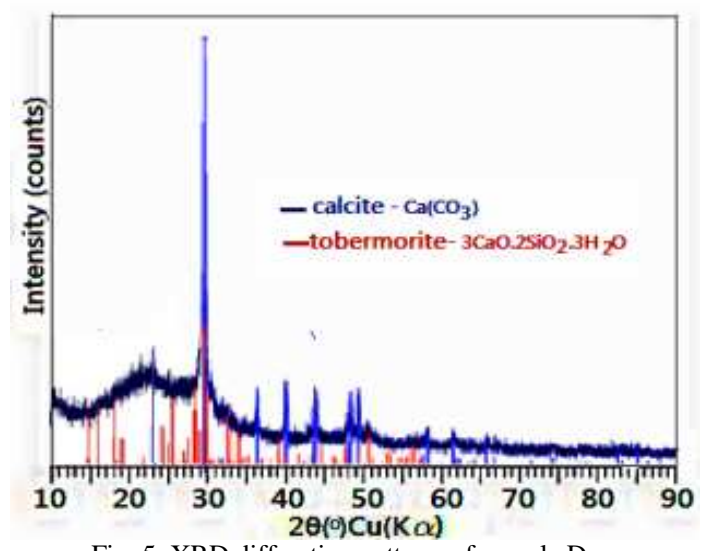

Fig. 5 XRD diffraction pattern of sample D

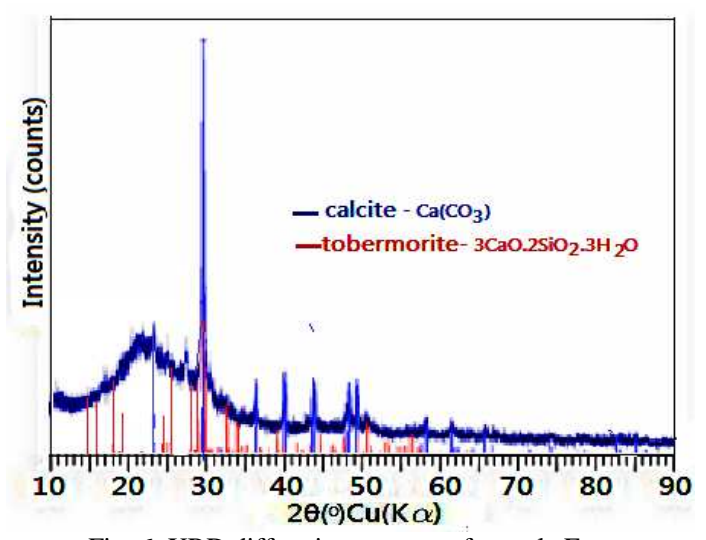

Fig. 6 XRD diffraction pattern of sample $\mathrm{E}$

\section{SEM Analysis}

The microstructure of each mixture ratio of sample A, B, C, D, and E can be seen in Fig. 7, 8, 9, 10, 11, 12, 13 and 14. Figs. 7 and 8 show the SEM mixture of rice husk ash and quicklime at a ratio of 0.25: 0.75 (sample A) and 0.35: 0.6 (sample B). Figs. 7 and 8 show that portlandite and calcite look like to dominate the microstructure of the mixture on both the mixture ratios. Portlandite formed as a result of the reaction of rice husk ash $\mathrm{CaO}$ and $\mathrm{H}_{2} \mathrm{O}$, whereas calcite formed from the reaction of $\mathrm{Ca}\left(\mathrm{OH}_{2}\right)$ and $\mathrm{CO}_{2}$. The presence of tobermorite was not shown in Figs. 7 and 8 may be caused by the low ratio of rice husk ash to quicklime.

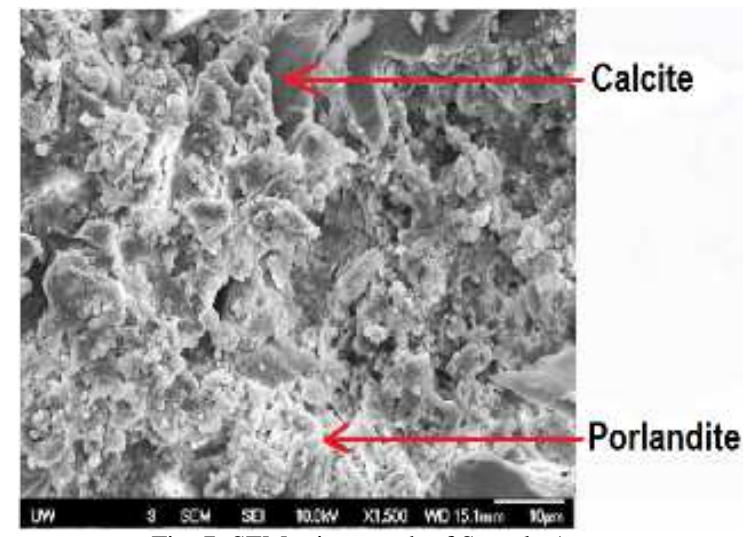

Fig. 7 SEM micrograph of Sample A

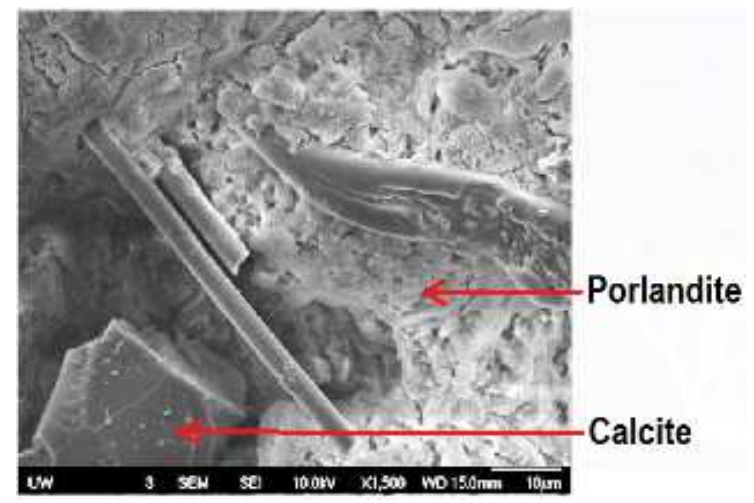

Fig. 8 SEM micrograph of Sample B 
Fig. 9, 10 and 11 show SEM mixture of rice husk ash and quicklime at a ratio of $0.5: 0.5,0.65: 12: 35$, and 0.75: 0.25 . Fig. 9, 10 and 11 show that the calcite saw still dominate the microstructure on the third mixture ratio. The appearance of the tobermorite formation initially slight can be seen in Fig. 9, the formation of tobermorite then grew in Fig. 10 and 11, while the portlandite formation was not seen anymore. This happens because portlandite has reacted with silica of rice husk ash to form tobermorite. Fig. 9, 10 and 11 also explained that the more the percentage of rice husk ash to the mix ratio, so the more tobermorite formed.

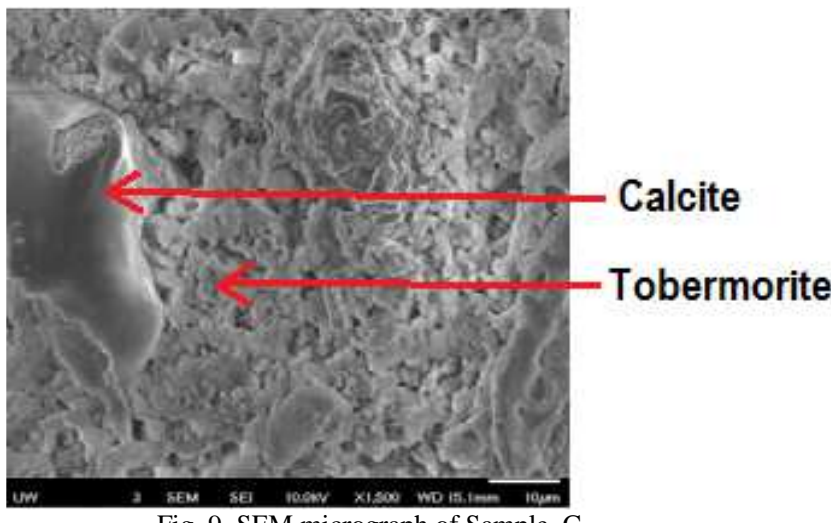

Fig. 9 SEM micrograph of Sample C

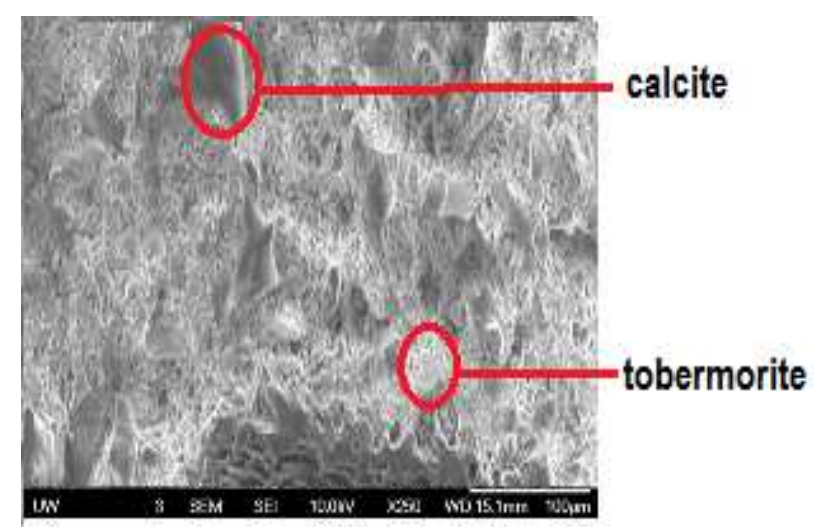

Fig. 10 SEM micrograph of Sample D

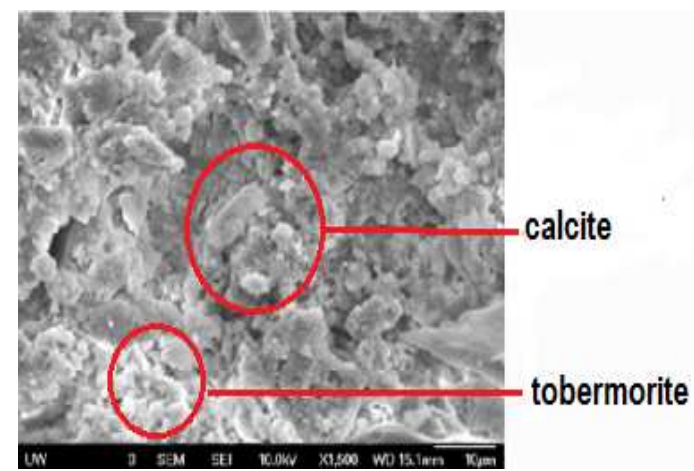

Fig. 11 SEM micrograph of Sample E

Fig. 12 shows an area of interesting fibrous tobermorite structures and Fig. 13 shows an area of laminar tobermorite structures. These different tobermorite formations resulted in different degrees of hydration between the reaction of cementitious materials and water. Tobermorite in fibrous structure formation and in laminar structure formation as well are an important as they are responsible for hardening the mixture pasta of rice husk ash and quicklime. Tobermorite as hydration product in terms of cement matrix system can be produced in two forms of calcium silicate hydrate as now designated as calcium silicate hydrate I (CSH I) and calcium silicate hydrate II (CSH II) . CSH I produced soon after cementitious materials added with water where $\mathrm{ca} / \mathrm{si}$ is low. CSH I is the product of the reaction between tricalcium silicate or dicalcium silicate and water. $\mathrm{CSH}$ II produced when ca/si is high as a result of the reaction between silica and calcium hydroxide. Morphology structure of tobermorite composed by CSH I is commonly in fibrous form, and morphology structure of tobermorite composed by CSH II is commonly in laminar form. The formation of tobermorite composed by CSH II can occur in few weeks during the hydration process in curing period after for about 24 hours in an initial period of hydration process. The use of rice husk ash as supplementary cement material to the Portland cement was found that when silica of rice husk ash reacts with calcium hydroxide to produce CSH II, the microstructure of the CSH II becomes more homogenous especially in interface zone [14].Tobermorite particles size are very small in nanoscale which is characterized by very small interlayer spaces and very large surface areas. These very large surface areas of tobermorite particles contribute to the strength of cement paste.

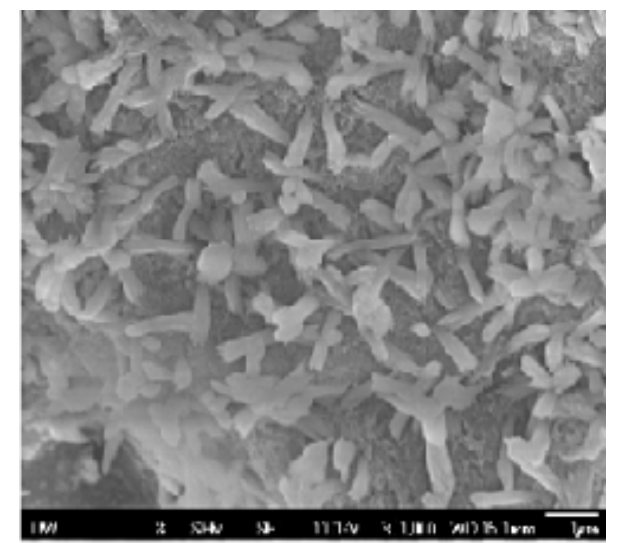

Fig. 12 Fibrous tobermorite structures

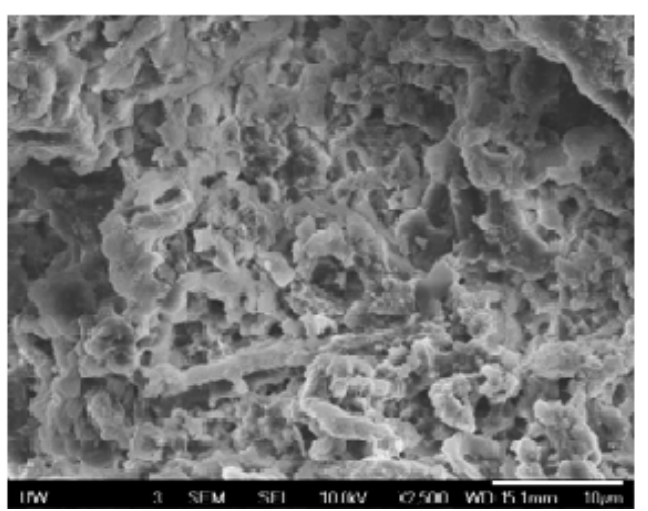

Fig. 13 Laminar tobermorite structures

In addition to portlandite, calcite, and tobermorite, hydration products of the reaction between rice husk ash and quicklime also contained various types of pore such as capillary pores or capillary voids as shown Fig. 14 . The pore distribution size formed after hydration process is the critical element influencing the cement paste strength and the 
number of hydration products such as tobermorite produced will affect the pore distribution size. The strength of cement paste will increase if porosity decrease due to the more hydration products produced during the hydration process. The presence of pores in the concrete is more concerned especially to its connection or disconnection system because of its influence on the permeability, shrinkage, and strength of the concrete. Disconnection of capillary pores on the outer concrete during curing period in cement-based materials inhibits water to penetrate inside the concrete to reduce the curing function [15]. Various types of the pore that can be produced during the hydration and curing process include gel pores, small and large capillary pores, large voids, interfacial zones, and microcracks. In terms of microstructure, the presence of capillary pores become more important in connection with the permeability because capillary pores have a great effect on the transport system for chemical ions of admixtures. The capillary pore is the voids that are not filled with hydration products in which its diameter is ranging from $10 \mathrm{~nm}$ to $50 \mathrm{~nm}$ in the cement paste with low water/cement [16].

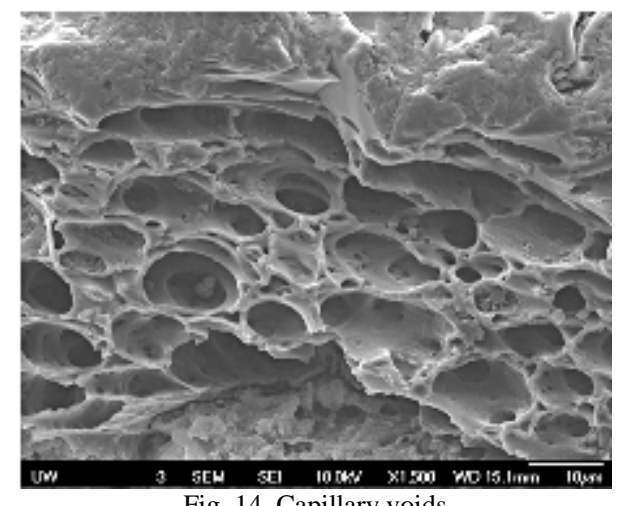

Fig. 14 Capillary voids

Hydration process of the reaction of silica of rice husk ash with portlandite will increase the tobermorite formation while reducing the portlandite formation. But the reaction of silica of rice husk ash and portlandite does not constantly result in tobermorite due to the various parameters. Those parameters include particle size distribution, specific surface area, shape, and surface properties [11], [17].

The surface area of rice husk ash is an important factor to the rice husk ash reactivity degree to form tobermorite because it provides a contact area to react with portlandite. High specific surface area of rice husk ash greatly contribute to its high pozzolanic reactivity. Pozzolanic reactivity of rice husk ash is the most important factor to produce hydration products such as tobermorite in cement matrix system. A finer rice husk ash has a larger surface area, and therefore it has higher reactivity degree to react with portlandite. The particle size of rice husk ash will be highly reactive if the particle size of rice husk ash is less than 11 $\mu \mathrm{m}$ [18]. The particle size of rice husk ash that is lower than $11 \mu \mathrm{m}$ is very reactive and can be used as supplementary cement material to produce high compressive strength of concrete. The influence of rice husk ash to various parameters in connection with rheologies such as viscosity, plasticity, and elasticity depends on particle size distribution, specific surface area, surface type and properties of rice husk ash. Rice husk ash is found as material for suitable rheology with average plastic viscosity and low stress [17]. The more percentage of rice husk ash is passing $12 \mu \mathrm{m}$ sieve, the more small particles of rice husk ash will react with portlandite to form a higher concentration of tobermorite. The percentage of rice husk ash used in this study that did not pass a sieve of $12 \mu \mathrm{m}$ is $25 \%$ may lead to reducing the reactivity of silica to portlandite to produce tobermorite in the hydration process. In addition, the percentage of silica of rice husk ash used in this study was $69.42 \%$ to form tobermorite.

There was interesting microstructure of jennite found in sample A. Although it was very difficult to detect jennite microstructure in sample A by using XRD analysis, the SEM analysis found the jennite microstructure as shown in Fig. 15. The structure of jennite look likes tobermorite in which central layer structure of both minerals are composed of $\mathrm{CaO}$ ribbed on side with continuous chains of silicate tetrahedral, but all atoms $\mathrm{O}$ of $\mathrm{CaO}$ are shared with silicate tetrahedral for tobermorite while only half atoms $\mathrm{O}$ of $\mathrm{CaO}$ are shared with silicate tetrahedral, and the remainder stays in $\mathrm{CaOH}$ [19]. Therefore, the difference between tobermorite and jennite is the presence of $\mathrm{CaOH}$ bonds in jennite.

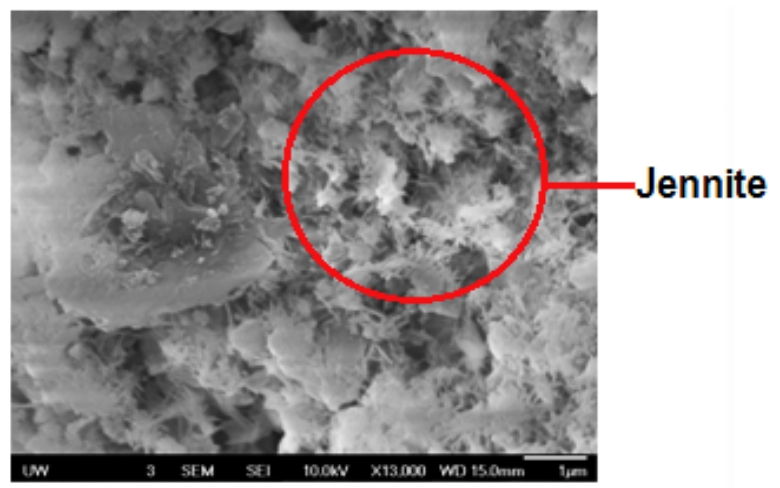

Fig. 15 Jennite microstructure in sample A

\section{CONCLUSION}

Pozzolan reaction of rice husk ash containing silica of $69.42 \%$ and quicklime containing calcium oxide of $93.75 \%$ can result in the formation of tobermorite especially in a mixture of rice husk ash and quicklime at a ratio of $0.5: 0.5$, $0.65: 0.35$ and $0.75: 0.25$. SEM analysis found jennite microstructure, a mineral looks like a tobermorite, in a mixture of rice husk ash and quicklime at a ratio of 0.25 : 0.75 .

\section{ACKNOWLEDGMENT}

The author thanks U.S. Department of State's Bureau of Educational and Cultural Affairs and the Council for International Exchange of Scholars (CIES) for the financial support under Fulbright Grant (Grant ID Assigned: 68121013) to carry out a part of this research at University of Washington, USA. Also, the author would like to thank Dr. Rajendra Bordia, was formerly as department head of materials science and engineering at the University of Washington, who gave the author the laboratory facility and discussed the results of this research and Kevin Strong, was a graduate student, who analyzed and discussed the XRD 
results. Finally, I would like to thank and respect to Dr. Randall Kyes, Director of Center for the Global Field Study University of Washington, as a host of Fulbright Scholar at the University of Washington.

\section{REFERENCES}

[1] J.G.J. Olivier, G. Janssens-Maenhout M. Muntean, and J.A.H.W. Peters, "Trends in global CO2 emission," Institute for Environment and Sustainability (IES) of the European Commission's Joint Research Centre (JRC), JRC Technical Note number: JRC98184, 2015

[2] Y.B. Jung, and K.H. Yang, K.H. "Mixture-proportioning model for low-CO2 concrete considering the type and addition level of supplementary cementitious materials," J. Korea Concr. Inst., vol. 27, No. 4, pp. 427-434, August. 2015.

[3] F.N. Shahmohamad, and S. Mousazade, "Effect of pozzolana on the environmental influence of cement industry," International Journal of Metallurgical \& Materials Science and Engineering (IJMMSE), vol. 5, no. 1, pp. 21 - 30, Feb. 2015.

[4] L.O. Ettu, I.O. Onyeyili, U.C Anya, C.T.G. Awodiji, and A.P.C Amanze, "Strength of binary blended cement composites containing afikpo rice husk ash," International Journal of Computational Engineering Research, vol. 3, no. 4, pp. 71-76, April 2013.

[5] L.O. Ettu, I.O. Onyeyili, U.C Anya, C.T.G. Awodiji, and A.P.C Amanze, "Strength of binary blended cement composites containing afikpo rice husk ash," International Journal of Computational Engineering Research, vol. 3, no. 4, pp. 71-76, April 2013.

[6] S. Munshi, G. Dey, and R.P. Sharma, "Use of rice straw ash as a pozzolanic material in cement mortar," IACSIT International Journal of Engineering and Technology, vol. 5, no. 5, pp. 603-606, October. 2013.

[7] G.K. Al-Chaar, M. Alkadi, and P.G. Asteris, "Natural pozzolan as a partial substitute for cement in concrete," The Open Construction and Building Technology Journal, vol. 7, pp. 33-42, 2013

[8] R. Ghosh, and S. Bhattacharjee, "A review study on precipitated silica and activated carbon from rice husk," J Chem Eng Process Technol, vol. 4, no.4, pp.156-163, April 2013.
[9] O. Kayali, J.M. Khatib, and M.S. Achmed, "The role of industrial by-products in creating sustainable concrete," Paper Presented at International Seminar of Innovation and Valorization in Civil Engineering and Construction Materials, Rabat, Marocco, November 23-25, 2011.

[10] A. El-Dakroury, and M.S. Gasser, "Rice husk ash (RHA) as cement admixture for immobilization of liquid radioactive waste at different temperatures," Journal of Nuclear Materials, vol. 381 pp. 271-277, 2008.

[11] A.N. Givi, S.A. Rashid, F.N.A. Aziz, and M.A.M. Salleh, "contribution of rice husk ash to the properties of mortar and concrete: A Review," Journal of American Science, vol. 6, no. 3, pp. 157-165, 2010 .

[12] K. Ganesan, K. Rajagopal, and K. Thangavel, "Rice husk ash blended cement: Assessment of optimal level of replacement for strength and permeability properties of concrete, " Construction and Building Materials, vol. 22, no. 8, pp. 1675-1683, Augustus, 2008.

[13] Portland Cement Composite Standard, SNI 15-7064-2004, Board of National Standardization, Jakarta, 2004.

[14] V. S. Nikam and V.Y. Tambvekar, " Effect of different supplementary cementitious material on the microstructure and its resistance against chloride penetration of concrete," Tech. Rep. of Advanced Materials for Construction of Bridges, Buildings, and Other Structures III, Vol. P5, Article 13, 2003.

[15] G. Sant, D. Bentz, and J. Weiss, "Capillary porosity depercolation in cement-based materials:Measurement techniques and factors which influence their interpretation," Cement and Concrete Research, vol. 41, pp. 854 - 864, April 2011.

[16] J.J.Thomas, A.J Allen, and H.M. Jennings, "Structural Changes to the Calcium-Silicate-Hydrate Gel Phase of Hydrated Cement with Age, Drying, and Resaturation,"J. Am. Ceram. Soc., 10: 1-8, 2008.

[17] A.I. Laskar, and S. Talukdar, "A new mix design method of highperformance concrete," Asian Journal of Civil Engineering, vol. 9, no. 1, pp 31-39, 2008.

[18] V. Sata, C. Jaturapitakkul, and K. Kiattikomol, "Influence of pozzolan from various by-product materials on mechanical properties of high-strength concrete," Construction and Building Materials, vol. 21, no. 7, pp. 1589-1598, 2006.

[19] P. Pourbeik, "Nanostructure and engineering properties of $1.4 \mathrm{~nm}$ tobermorite, jennite and other layered calcium silicate hydrates," PhD. Thesis, Unversity of Ottawa, Canada, 2015. 